\title{
UN INTENTO DE APROXIMACIÓN AL NEOCONSTITUCIONALISMO
}

\author{
An attempt to approach the neo-constitucionalism
}

Ricardo Salas Porras

\begin{abstract}
Resumen: Este ensayo trata de realizar una acercamiento a las condiciones extrajurídicas en las que surgen el constitucionalismo clásico y el así denominado neoconstitucionalismo. A través de un análisis doctrinario, plantea los rasgos y contribuciones más sobresalientes de estas corrientes de pensamiento. La importancia de este fenómeno en América Latina, más que un cambio en la visión que se tiene de la primacía de los principios constitucionales, se encuentra en un cambio de visión sobre la fuente efectiva de los mandatos jurídicos y su legitimidad política. Ese cambio de visión puede implicar modificaciones en la forma de abordar contenciones fundamentales (abiertas desde hace muchos años en algunos países), cuya respuesta ha sido ensayada a partir de diversas razones jurídicas, a menudo suspendiendo en su efectividad los principios constitucionales.
\end{abstract}

Palabras clave: constitucionalismo clásico, neoconstitucionalismo, mandato jurídico, legitimidad política, resolución de controversias fundamentales.

\begin{abstract}
This essay tries to make an approach to extralegal conditions in which the classic constitutionalism and the so called neo-constitutionalism arise and develop. Through a doctrinaire analysis the essay states the main features and contributions of these schools of thought. The importance of this phenomenon in Latin America, more than a change in the way we see the primacy of constitutional principles, means a change of viewing the real source of legal mandates and their political legitimacy. This different perspective may involve changes in how we solve fundamental disputes (open for many years in some countries), whose responses have been tested from various legal reasons, often suspending the effectiveness of constitutional principles.
\end{abstract}

Keywords: classic constitutionalism, neo-constitutionalism, legal authority, political legitimacy, resolution of fundamental disputes.

\section{Principios constitucionales y ley}

La relación entre ambos ha sido normalmente concebida como complementaria. Sin embargo, ya sea al confrontarlas críticamente entre sí o al tener que dirimir hipótesis específicas, dicha relación se revela como tensa y, a menudo, conflictiva.

La médula de la cuestión está en dónde se pone el acento o se identifica la fuente de los mandatos. No en el sentido puramente de teoría de la jerarquía

\footnotetext{
* Ph. D. Abogado y politólogo. Catedrático de la Facultad de Derecho de la Universidad de Costa Rica. Correo electrónico: salascr@gmail.com

Este artículo fue recibido el 10 de junio de 2016, siendo aprobada su publicación el 5 de octubre de 2016.
} 
normativa, que indudablemente confiere a los postulados constitucionales la calidad determinante (o de denominador, se diría en números fraccionarios; o, tomando prestada una categoría lacaniana, de "significante amo"), sino de autoridad efectiva.

Durante décadas los sistemas jurídicos de muchos países se han regido por el imperio de la ley, más que de los postulados constitucionales. A pesar de que, como acto de fe, se declare el predominio de la Constitución sobre todas las otras fuentes y cuerpos normativos, lo cual es conforme a una de las acepciones más difundidas del Estado de Derecho, lo cierto es que tanto la Constitución cuanto los principios constitucionales (que al tener que ser desentrañados y no ser obvios para el juicio no avezado), han quedado en una pura declaración, otorgándose el valor mandatorio a la ley y otras normas, mientras que aquellos quedan disminuidos a píos propósitos.

El asunto es más que una cuestión de puro "sistema jurídico" o del valor del mero texto constitucional (cuando la discusión es a ese nivel, es probable que los principios constitucionales ni siquiera sean considerados). Es una cuestión de epistemología jurídica y necesariamente de epistemología política. Hace alusión a dónde está la soberanía y quién o qué manda: si los acuerdos básicos de la sociedad y lo que aparece (muchas veces subyacente) en la Constitución, o bien el legislador común y la ley. Si acomodándose a una de las dos grandes concepciones de la modernidad política, como sostuvieron los más sobresalientes constituyentes de la república que aglutinaría las trece colonias norteamericanas, se respondiera que el referente insoslayable es el acuerdo constitutivo y no la ley ordinaria, que está sometida a las vicisitudes cotidianas, la tensión se estaría resolviendo en pro del constitucionalismo. Reitero no como sinónimo de Estado de Derecho, sino como corriente que concibe los postulados constitucionales y los principios que los sostienen como un determinante siempre presente y vinculante. Si, recogiendo la visión expuesta por Montesquieu y acogida por los revolucionarios franceses que cifraban la soberanía de la Nación en sus representantes (ya se tratara de la Asamblea Nacional o la Convención) y por ende en la ley que ellos emanaban, se dijera que son estos dos factores los efectivamente dominantes, se estaría optando por esa segunda concepción. Se podría aventurar que los primeros estaban más movidos por las características del acuerdo y su vigencia, para asegurar que la república que intentaban fundar fuera una realidad duradera; mientras que los segundos ponían su énfasis en una realidad política de masas movilizadas y qué exigían. Lo importante es que, independientemente de las circunstancias en que tuvieron origen, ambas visiones tienen corolarios poderosos en la forma en que se entiende y resuelve la mencionada tensión. Por eso se decía que, más que un simple asunto de clase de "sistemas jurídico", es de cómo se concibe la fuente efectiva del mandato y la relación entre los postulados constitucionales y la ley.

Es en el marco de esa relación de prevalencias entre una u otra concepción que, después de un prolongado dominio casi exclusivo de la ley (no es casual que se hablara del "imperio de la ley"), la mutación de los factores políticos que se verá más adelante, pueda estar empujando hacia un reposicionamiento del constitucionalismo como concepción dominante. 
En efecto, más que su significado ontológico (concediendo en gracia de discusión que tenga alguno), su impacto es sobre todo a nivel de la epistemología jurídica, pues representa una forma diferente de ver las cosas y de posicionarse ante el debate troncal del Derecho Constitucional. Por otra parte, no se trata de un fenómeno o sucesión de estos que sea novedoso en todas partes, ni exclusivo de nuestro medio. Finalmente, viéndolo con detenimiento se constata que no es una corriente o un algo que nos sobrecogió de repente y sin aviso a los que nos vinculamos al debate constitucional (que hoy en día abarca a casi todas las personas), sino que desde hace tiempo viene y va, aparece y reaparece con más o menos fuerza, pero nunca ha dejado de estar.

En todo caso, discurrir sobre el neoconstitucionalismo no deja de ser azaroso y hasta riesgoso. En tiempos en que los neos sustituyeron, al menos de momento, a los post y se habla de neoliberalismo, neoconservadurismo, neomarxismo, neofascismo, neocontractualismo, neokantismo, neoclacisismo o neoconductismo, entre otras cosas, sería sospechoso que faltara el neoconstitucionalismo. Es azaroso porque la cantidad de objetos o eventos a los que se puede hacer alusión con un término tan elástico puede ser muy amplia creando un estado de incertidumbre teórica casi esotérica. Es riesgoso, porque puede llevar a discusiones no solo estériles en el renglón de productos políticos y jurídicos, sino porque implica un desgaste de energías de las que los estudiosos normalmente andan ajustados.

Por eso vale hacer la delimitación mínima e inicial de qué entiendo por neoconstitucionalismo para después entrar a explorar una de sus variaciones más interesantes (la que estimo resulta más productiva y apta a la pretensión de un espacio social pluralista), no sin antes examinar uno de los planteamientos más conspicuos del constitucionalismo clásico en el cual encuentra su arraigo.

\section{Esbozando una definición del neoconstitucionalismo}

Para establecer una definición mínima del neoconstitucionalismo desde la cual partir, no podría prescindirse de tres o cuatro elementos. El primero consiste en la existencia o toma progresiva de conciencia y voluntad política de que existen normas sustantivas que, más que beatos objetivos o finalidades de los poderes públicos y las diversas dimensiones del espacio social que intentan ordenar, son mandatos operativos que deben ser implementados. Para decirlo de otra manera, es cada vez más presente la tendencia a crear nuevas normas constitucionales pensadas para ser efectivas; o bien la mayor conciencia y voluntad política de hacer que aquellos que antes se estimaba que eran preceptos puramente declarativos (o anteriormente denominados "programáticos") se vuelvan aplicables y de ponderación insoslayable cuando se discute cualquier tema al que, por ligeramente que sea, puedan contribuir a dirimir. A diferencia de épocas pretéritas hay un cambio en la epistemología jurídica con que los operadores del derecho se aproximan y comprenden la ingeniería constitucional. Cada vez se trata menos de que hay una serie de disposiciones destinadas únicamente a estar escritas y con un estatuto autolimitado de no ser nada más que "valores" y no 
mandatos aplicables. También cada vez se trata menos de que estos estén consignados única y exclusivamente en el texto constitucional (y, por extensión, en los tratados internacionales) quedando en la inexistencia jurídica primaria cualquier otra norma que no se encuentre recogida allí. Se trata, por el contrario, de conferir vigencia efectiva al conjunto de normas constitucionales, sea porque estas se encuentran consignadas en la Carta Magna o porque tienen un valor incluso subyacente al texto escrito aunque no aparezcan explícitamente declaradas, pues se estima que son parte de la articulación política misma en torno a la que se ordena ese espacio social y sus actores. De ahí la diferencia griega entre syntagma y politeia, ambos términos con que se hace alusión al significante que hoy en día llamaríamos "constitución", pero con significados diferentes. Es más, sin que se trate de un deslizamiento hacia la tesis de las "normas pétreas" cuya epistemología es inmovilista y contraria a la del neoconstitucionalismo (pero paradójicamente podrían llegar a la misma conclusión en ciertos casos específicos), se trata de entender que incluso las normas que se hallen en la constitución escrita o syntagma pueden ser inconstitucionales por oponerse a la politeia o los acuerdos políticos básicos en torno a los cuales se vertebra un espacio social y sus distintas dimensiones. En alguna doctrina italiana se diría que la diferencia entre esas categorías es análoga a la que media entre "Constitución formal" y "Constitución material", en ese orden; pero es más que eso, pues no versa solamente acerca de cómo se organizan los poderes públicos o sus potestades, sino sobre los acuerdos básicos de la sociedad. Y esto sí que puede quitarle el sueño a más de uno y hasta suscitar una reacción inicial de estupor y rechazo a quienes crecimos intelectualmente con un paradigma epistémico anterior.

En resumen, se trata de que (a) las normas escritas de la Constitución Política dejen de ser una pura declaración de buenos propósitos y se vuelvan de acatamiento y observancia inevitables; (b) en cualquier asunto de interés público y de resguardo a la autonomía privada, por poca monta que aparente; y (c) que debe admitirse sin remilgos que hay normas constitucionales que pueden no estar en la constitución escrita e incluso supeditar a las que sí están.

A propósito de estos postulados debe descartarse decididamente que exista un regusto moralista en el neoconstitucionalismo, como erradamente se dice en algunos foros. No se trata de introducir la moral (ni el Derecho Natural, podría añadirse, para no omitir categorías que aunque caídas en la obsolescencia, tuvieron un peso mayúsculo) en el discurso constitucional. Es tomar en cuenta los acuerdos políticos básicos que presiden un orden social. Es política, con la intersubjetividad y la necesidad para la convivencia que esta implica. No es moral.

Este cuadro, que habrá quien lo mire como una pintura de Picasso, no nos es del todo extraño. Por ejemplo en mi país, Costa Rica, el gran mérito de la creación de la Sala Constitucional, fue justamente "legalizar" (o poner en vigencia efectiva) la Constitución Política. Es decir, que fuera tan vinculante y tan vigente como cualquier otra ley y más superando así el pobre estatuto de simple referencia simbólica que hasta entonces se le había atribuido en los asuntos de importancia (porque en los de poca relevancia ni se tomaba en cuenta). También desde entonces la añeja diferencia entre 
normas "preceptivas" y "programáticas" (aquellas cuyo cumplimiento estaba diferido sine die y fungían más como una estrella Polar, que sirve para orientar pero se sabe que se está destinado a nunca llegar), se trastocó y las que antes eran declaraciones axiológicas empezaron a tener repercusiones empíricas. Igualmente, otras normas esenciales para la convivencia en una sociedad con los valores políticos como los que aparecen en muchas constituciones o en los tratados, aun cuando no aparecieran escritas en esos cuerpos, pasaron de ser párrafos de emotiva retórica a condicionar el quehacer de los poderes públicos o incluso a condicionar y reconducir las normas escritas que sí estaban en esos textos. En Costa Rica, por ejemplo, se dio el caso de que la Sala Constitucional desautorizó el referendo popular (estatuido en la Carta Magna) cuando lo que se discute son derechos esenciales de las personas. En general podría decirse que el discurso de los Derechos Humanos, por lo menos en su parte más elemental, entró al ordenamiento constitucional costarricense por esa vía, ya que fuera contemplado o no en un texto escrito, lo cierto es que su jerarquía superior no ha sido cuestionada. Me auguro que algo similar suceda en poco tiempo con los derechos sociales y a la pluralidad/diversidad.

De lo que sí podemos estar seguros es que esta nueva visión del fenómeno constitucional exige la creación y empleo de nuevos parámetros interpretativos, pero ante todo cognitivos. La simple lectura literal de los preceptos individuales (independientemente de su jerarquía) no basta, sino que es menester ineludible confrontarlos siempre con el telón de fondo de valores generales, que amén de inspirarlos (si es que en verdad los inspiran), deben servir para definir su contenido efectivo y sistematicidad conjunta. La comprensión literal de la norma y su sentido, o el del conjunto de ellas, ya no es suficiente y en ocasiones puede inducir a error, si es que no se tiene como referente el conjunto de valores generales que dan sustento al orden básico, como son la autonomía de la voluntad, la igualdad, la proporcionalidad, la rendición de cuentas, la razonabilidad, el principio pro libertate, pro homine o pro natura, solo por citar a título enumerativo algunos que han adquirido carta de ciudadanía plena.

De tal forma que, lenta pero continuamente, el neoconstitucionalismo como propuesta teórica ha impulsado una modificación hacia lo que hoy nos parece un hecho incontrovertible: es una nueva forma de comprender las normas constitucionales en cada contexto y de reconstruir su alcance, pero también es un novedoso instrumental para la ingeniería constitucional. Dicho de otro modo, si bien la teoría siempre creó el objeto de estudio, aunque dijera que solo lo describía, lo explicaba y lo analizaba, ahora más que antes está patente que la teoría constitucional, desde el enmarcamiento gnoseológico del neoconstitucionalismo, tiene por meta la reelaboración del mapa constitucional en conjunto y su viabilidad empírica, creando normas incluso donde se decía antes que no las había. Por eso, más que otrora, se puede hablar de un amplio esfuerzo de ingeniería constitucional.

Se llega entonces al punto de tener que admitir que el así denominado neoconstitucionalismo, más que una corriente teórica en sí misma, es un cambio en la cultura jurídica que no se agota en la hermenéutica normativista, ni en el proceso de construcción del precepto, sino que está mucho más acá y va mucho más allá, en el 
sentido que precede tanto la construcción y la interpretación normativa, y le confiere corolarios que muchas veces no estaban inicialmente contemplados o incluso, pueden estar explícitamente excluidos de ese precepto jurídico; todo en virtud de un esquema valorativo que se concreta en cada vicisitud, haciendo prevalecer otros criterios o juicios de carácter más general y alcance más profundo. No se trata solo de "desempacar" lo que nunca se había sacado, pero estaba allí contenido. Se trata de una verdadera "reconstrucción".

Nótese que, sin que se haya tomado plena conciencia de ello, incluso la noción misma de soberanía estatal ha cambiado y ha venido en repliegue (por lo menos respecto a las nociones hasta ahora convencionales de la misma, que van desde Bodin hasta Weber). Ya no se trata del Estado y su ordenamiento interno, ni de los compromisos internacionales que ha adquirido, sino en la forma en que estos son interpretados, complementados y hasta recusados o suspendidos, si es que se entiende que se oponen a los valores básicos (sean subyacentes o no) del ordenamiento constitucional en una sociedad determinada y su correlación interna de poderes.

Un dato como ese, que todos hemos visto y vivido, solo esporádicamente y a regañadientes se admite por los sectores más resilientes a estos cambios; pero lo inobjetable es que está presente entre nosotros desde hace mucho tiempo. Por eso ya forma parte de nuestra cultura jurídica. Y esto me lleva al último aspecto de esta definición de las características mínimas de lo que con alguna holgura se apela como neoconstitucionalismo: que es un asunto esencialmente de cultura política.

Me refiero no solo a que, como es sabido, el Derecho es la política llevada al plano de la coactividad formalizada (punto este último que, como atinadamente señaló Kant, lo diferencia de la nuda coactividad), sino a que es un asunto del quehacer cotidiano. El macrodiscurso político suele ir por caminos más o menos publicitados o manifiestos; no así la práctica política. Lo mismo vale para el Derecho en el que las normas o postulados, aun cuando su proliferación y especialización los hagan un dominio ignoto para muchos (y casi iniciático), lo cierto es que la exigencia moderna es que estos deben ser conocidos y manifiestos o por lo menos declarados. La cultura jurídica, a diferencia de lo anterior, normalmente no se declara ni se reconoce con facilidad como parte del fenómeno jurídico convencionalmente entendido, sino que se la tiene como una cuestión puramente práctica o de estilo. Como diría Todorov, la cultura es esencialmente lo que no se dice y se hace. De ahí la dificultad de familiarizarse con una que no es la materna.

Esto lleva a ciertas inferencias de relevancia. La primera, es que puede darse una discontinuidad o contraste entre lo que se postula y lo que efectivamente se hace. La historia constitucional está plagada de esos ejemplos. Piénsese en la igualdad y libertad de las personas (cosa que era proposición cruel y dolorosa para quienes todavía eran esclavos o para quienes todavía están sujetos a condiciones de opresión), el acceso a la salud, a la educación o al ejercicio de controles sobre la Administración Pública y la sujeción de esta a la ley. Pero, bien visto el punto, se percibe que no se trata de un caso de hipocresía política colectiva, en que se sabe que se dice una cosa y se hace otra. Es 
más complejo que eso. Es un síntoma completamente ideológico (y, en este caso, entiendo por ideología lo que nos hace creer en ciertas cosas a pesar de que somos testigos de que no son así, pero preferimos creerlas porque las consecuencias de admitir lo contrario las estimamos muy onerosas o incluso catastróficas), en el que el arco de visión se provee de un punto ciego a fin de evitar que este opere como un contraste grosero que deje en el aire todo lo que se declara. Por eso es que, como el rey desnudo, cuando esa circunstancia se pone en evidencia las reacciones no siempre son políticamente apacibles, porque es poner en entredicho parte del mundo de cosas que sostiene nuestra vivencia constitucional. Por ende, al decir de Robert Dahl, lo verdaderamente relevante es preguntar qué es lo que hacen las instituciones todos los días, no lo que declaran o sus funciones manifiestas. Más que estas, importan las latentes. Es eso lo que da la verdadera dimensión de la vivencia constitucional, que no puede estar ubicada sino en el estrato de la cultura jurídica.

Algunos autores podrían tratar esta distinción con el consabido binomio validez/vigencia, pero es asimismo mucho más complejo que eso. Es analizar los factores que posibilitan, impiden o dificultan que las normas abstractas se transformen en hechos concretos. Aun más, es demandar que incluso aquello que no está normado, pero se identifica como necesario después de una valoración política sana, entre a tener presencia en el debate jurídico y tenga efectos plenos en la solución jurídica de las diversas vicisitudes en que tenga algo qué decir.

La segunda inferencia de relevancia radica en que, tratándose de una cuestión de cultura política y tomando en cuenta lo comentado en las líneas anteriores no basta su simple aceptación, sino que debe ser parte de un proceso de apropiación social por parte de la mayor cantidad de actores. De lo contrario, nuevamente, si es que ya reviste el carácter de precepto jurídico estará condenado al desuso y su descrédito acumulativo (muy propio de aquellas normas que se emanan con propósitos simbólicos o puramente declarativos, pero que se sabe de previo que no van a ser cumplidas, lo que solo lleva a incrementar la inflación normativa y la deslegitimación del Derecho y el sistema político en que se asienta); si no es ley, será de aplicación restringida a ciertos foros muy contados (digamos los tribunales constitucionales), dejando que los demás (incluyendo los parlamentos, despachos administrativos y la actividad pública en general) caminen por otros rumbos.

Finalmente se infiere que, para asegurar la efectividad de esas valoraciones abstractas, es preciso acudir a conocer cuáles son los mecanismos de adopción, veto o digestión en cada espacio social, porque cada uno tiene sus propias características. La apropiación no es igual entre una comunidad indígena marginada que entre los jóvenes del e-world; ni entre los funcionarios públicos de nivel medio que entre los patronos de las industrias exportadoras de frutas. Cada uno tiene una visión diferente del mundo, si bien hay algunos rasgos límites históricamente determinados. Sin embargo lo cierto es que ese proceso de apropiación no es homogéneo, por lo que no se puede esperar que tenga en todos los espacios sociales las mismas repercusiones, ni puede descuidarse su devenir interno. 
En síntesis el neoconstitucionalismo, tal y como se ha venido dibujando en las páginas anteriores, es un fenómeno básicamente de vocación empírica, en que, a partir de lo jurídicamente estatuido, se requiere acudir a criterios de justicia política, según defendía John Rawls para definir si el Derecho que se tiene al frente es suficiente o hay que complementarlo (Rawls, 2001: 48) o si es injusto por no acomodarse a aquellas valoraciones generales, en cuyo caso, por mucho que exista una norma superior (incluso constitucional) que le sirva de sustento, hay que lograr una aplicación que se acomode a aquellas y no a esta.

\section{Los planteamientos más relevantes}

Pasemos ahora a una de las corrientes del constitucionalismo clásico y otra del neoconstitucionalismo. Indudablemente pueden ser múltiples las corrientes y asociaciones estudiables. En lo particular la que me parece más rica, tanto en sus aportes efectuados cuanto en su potencial, es una díada algo llamativa, pero que durante los años de tratar de conocerla mejor y estudiar sus propiedades me parece que puede representar un planteamiento político-jurídico de amplio espectro. Pero ante todo, apto para un sociedad que tiene entre sus cánones medulares lograr la vigencia de un Estado Social de Derecho; que, por una parte, soporte los embates de los sectores que se muestran (ahora o desde siempre) disconformes con el Estado Social o con el Estado de Derecho; y que, por la otra, pueda salir avante en un mundo cada vez más complejo donde las reglas jurídicas muchas veces no están en capacidad de resolver (en tiempo o calidad) las contenciones que se presentan (de lo que, por cierto, se valen aquellos sectores para abogar por reducir o revocar el Estado Social y el Estado de Derecho).

No se crea que es un sistema teórico ideado por este servidor ni mucho menos, sino que tiene presencia (algo inorgánica, hay que reconocerlo) en la literatura más sobria y fecunda; a pesar de las diferencias históricas de sus diversos pensadores. De todos los viables me quedo con dos que a mi juicio considero capitales, tanto por su contribución como por el papel personal cumplido, en el que fueron actores consistentes con sus planteamientos. Me refiero al fundacionalismo constitucional de James Madison y al derecho flexible o estado constitucional de Gustavo Zagrebelsky. Cada uno de ellos ha ameritado estudios más profundos que el presente. Sin embargo, en este ensayo se puede aseverar con convicción que, en conjunto, contribuyen a formar un complejo teórico de formidables dimensiones, el cual tiene mucho que decir del binomio constitucionalismo clásico-neoconstitucionalismo, tal y como fue arriba reseñado.

\section{a) La fundación de una república: James Madison}

De James Madison se pueden decir cosas muy interesantes, como haber sido el principal redactor de la Constitución de los Estados Unidos, cuarto presidente de ese país, uno de los tres más insignes promotores del esquema federalista del mismo, entre otras cosas. Conste que no se aborda aquí la parte más importante de su obra, 
como es su aporte a la construcción de un sistema político (o fundacionalismo político). Lo que más interesa para los fines de este artículo es su teoría constitucional que, si bien es cierto ha sido de invocación frecuente en los Estados Unidos, no ha resultado completamente adoptada ni lo ha sido de manera uniforme, sino que con frecuencia es blanco de reservas e interpretaciones bizarras de sectores con una visión restrictiva de la vivencia constitucional. En América Latina, por su parte, salvo contadas excepciones, se le ha dedicado muy poco estudio, por no decir que nada.

Los textos de mayor grosor teórico en la materia, los encontramos en los escritos de El Federalista, que es una obra conjunta de Madison, Hamilton y Jay. Entre estos, destacan diez ensayos (pp. 10, 38-43, 47-49), todos de Madison en los que, amén de una profundidad política poco frecuente, quien iba a ser el cuarto presidente de los Estados Unidos sienta las bases de una teoría constitucional que, como todos los clásicos, nunca deja de decir lo que tiene que decir.

Quizá el rasgo más sobresaliente de esa teoría constitucionalista de Madison es algo que hoy nos resulta una verdad de Perogrullo, pero que entonces no lo era. Precisamente por la importancia de ese rasgo y las consecuencias que ello tenía en la estructuración de la sociedad se volvió un canon común que actualmente pocas personas refutan (al menos abiertamente, si bien sistemáticamente se alejan de él). Me refiero a que la soberanía reside en la Nación (Madison, 1999: 208). Ese aparentemente simple postulado, significó un giro copernicano de cómo se entendía el quehacer político y, sobre todo, el proceso de ordenamiento normativo de las sociedades.

A diferencia de como sucedía cuando se estimaba que el soberano era el rey, emperador, regente, príncipe o quien fuera, del cual dimanaba el poder o como diría Norberto Bobbio, "ex parte principis"; la Revolución Americana (así denominada por los propios ingleses) marcaba una ruptura de este esquema y lo ponía en forma literal de cabeza, pues se recusaba ese paradigma cognitivo de que el poder descendía (de Dios, de la naturaleza o el designio de los hados) a la corona y que esta lo ejercía según su entender. Al romper con la unidad del Estado colonialista al que estaban sujetos más que un acto de independencia en sí mismo, lo cual fue progresivo, los revolucionarios americanos (luego estadounidenses) rompían de cuajo con la concepción de que el poder radicaba en la corona, que era el meollo mismo de esa unidad política. Esto implicaba que la fuente del poder político en su legitimidad radicaba en otro lado, que no podía ser más que el "pueblo". Se imponía la visión "ex parte populi”, que hasta ahora se sigue esgrimiendo.

Si bien ha de reconocerse que en las propias colonias americanas que se independizaban, la construcción de ese nuevo paradigma de que la soberanía reside en la Nación no fue fluida, sino que estuvo plagada de controversias en cuanto a su alcance y significado (quiénes integraban la Nación, qué se entendía por "pueblo" o quiénes lo componían y quiénes quedaban fuera, ya que por ejemplo ni las mujeres ni los negros formaban parte de él), siendo simultáneamente un recurso retórico frecuente para ejercer el poder en su nombre, pero en ausencia de la gente y simplemente arrogándose su representación, lo que resulta indiscutible es que esa 
concepción desarrollada por los revolucionarios norteamericanos, años antes de los franceses, marcó un hito en cómo se entendía la legitimidad del poder político y sus fuentes la cual hasta hoy sigue siendo una regla que pocos se animan a desafiar (como se dijo, al menos abiertamente).

Sin embargo, más que el tema de epistemología política que eso significó lo que nos resulta relevante es (como tenía que ser) sus secuelas para la ingeniería constitucional y su praxis. Al denunciarse la falsedad de que el poder proviniera de una fuente externa (mito este que, indudablemente, favorecía al poder monárquico colonialista, que durante siglos se había valido de esa concepción) y tratar de instalar la concepción de que este provenía del quehacer humano en sí mismo (cosa que ya había defendido magistralmente Maquiavelo), se desplazaba el eje de legitimidad al ser humano y el tejido en que estaba inserto. Por ende, este y no el gobernante era el titular originario del poder. O sea, el titular no es el apoderado, sino que este es un simple depositario temporal al cual se le entrega y se le puede quitar, que tiene que dar cuentas a su soberano (ya no el rey, sino el pueblo), pero principalmente que no puede atribuirse facultades que aquel no le ha concedido. Y he aquí el punto capital.

A nivel de diseño y práctica constitucional ya no se trataba como en las épocas pretéritas de que las facultades del monarca o príncipe fueran omnímodas y solo limitadas por graciosas concesiones hechas a los súbditos (digamos en materia de impuestos, libertades religiosas, civiles o políticas), sino al contrario. El ambiente originario es de libertad, que se constituye en la regla y que solo se limita por el poder público en tanto le es conferida esa facultad por parte del pueblo. En otras palabras, salvo aquello que por concesión de la Nación está prohibido, lo demás es un ámbito ilimitado de libertades. Es aquí cuando encontramos lo que para nosotros ahora es un viejo conocido: el principio de legalidad; aunque, como se sabe, este ya es un componente primario del constitucionalismo tradicional.

El que en definitiva es un componente que ese constitucionalismo tradicional no recogió, pero sí se halla en la obra de Madison y sus compañeros de causa es el principio político habilitante de esas limitaciones: la buena convivencia. Este no es sino hasta mediados del siglo XX que empieza a ser reconocido como un valor constitucional esencial, con un estatus también subyacente o preconstitucional de tal fortaleza que puede incluso supeditar la Carta Magna. Su rescate, huelga decirlo, corre en buena parte a cargo de eso que llamamos neoconstitucionalismo.

La densidad de esa concepción reside en que no es por sí sola la norma (de cualquier jerarquía que esta sea) la que habilita al poder público para marcar sus competencias ni justificar su ejercicio. Más allá de esa norma y su existencia ha de encontrarse un sustento legitimante, pues ella no se legitima a sí misma. El Derecho no se legitima a sí mismo, por mucho que se trate de un ordenamiento constitucional correctamente estructurado. Su verdadera legitimidad es preconstitucional y yace en la buena convivencia de las personas. Estas se agrupan para vivir mejor que en solitario. En consecuencia la delegación de poder que se le hace a la organización política encuentra por razón esa finalidad. El poder no se delega para vivir peor o meramente 
por hacer una concesión a los gobernantes, sino para que, mediante esa concesión, sea viable una buena calidad de vida conjunta. En sentido inverso, si esa norma o la acción del poder público, no son conducentes o funcionales a esa vida en colectivo, serán ilegítimas, por mucho que encuentren apoyo en la ley o en la norma constitucional misma. De tal suerte que la regulación sobre lo que no impida la convivencia social o sobre lo que no cree un peligro o lesión para los congéneres o para un régimen de convivencia en que estos puedan ejercer derechos similares, se contrapone a ese valor preconstitucional; o sea, este es un "coto vedado" para el poder público que bien que mal hoy es aducido (con diferente significado, pero con el mismo significante) como los derechos fundamentales. Por ejemplo, la incursión en ámbitos de la vida privada de las personas, sus creencias o sus prácticas, está fuera del alcance de la ley y son patrimonio exclusivo de su titular como lo han proclamado rimbombantemente muchos textos constitucionales que son irrespetados en forma flagrante todos los días. Antes bien, la obligación política y también de diseño y práctica constitucional es asegurar el respeto incondicional a esos amplios espacios de escogencia individual o de autonomía colectiva. Así verbigracia, por mucho que aparezcan en el texto constitucional o sean fruto del voto masivo de la ciudadanía, la confesionalidad de un Estado, las restricciones a decisiones y modos de vida que no afecten a los demás, ni les impidan el ejercicio de sus propios derechos o bien la regulación de las creencias de las personas, son postulados o restricciones ilegítimos y, por esa vía, en términos madisonianos, inconstitucionales. En resumen, la teoría política fundacionalista de Madison y el neoconstitucionalismo que se deriva de ella establecen que incluso la constitución puede ser inconstitucional. Es a esos referentes políticos esenciales a los que ha de mirarse al diseñar el orden normativo y su aplicación cotidiana. Y esto, como decía John Rawls, no vincula solamente al constituyente, al legislador o al juez, sino a todos y cada uno de los integrantes de esos cuerpos deliberantes cuando se tomen decisiones de índole pública (Rawls, 2001: 4041); esto es, vincula primariamente a cada ciudadano o ciudadana que debe velar porque sus decisiones se orienten por esos criterios y le exija a quienes ejercen el poder público proceder de conformidad.

La forma de reconocer esas prácticas subyacentes o decisiones originarias del pueblo, que no son las decisiones que al calor de los hechos inmediatos se pueden tomar o bien con el aprovechamiento de una mayoría política transitoria, es no solo realizar un esfuerzo de análisis político para definir cuáles son las coordenadas fundamentales de un orden social dado, sino identificar cuáles son los grandes y sólidos referentes normativos en que se han traducido. Es por ello que, contra la mayoría transitoria (recuérdese que la tarea que tenían de frente era la construcción de una "república", tanto en cuanto al reparto de las funciones como con relación a la participación popular, si bien no gustaban del término "democracia"), se erguía la enduring majority, que era un indicio importante para determinar cuáles eran esos criterios o valores esenciales que podían supeditar el poder público y sus ordenamiento autorizante (Dahl, 1970: 26).

Este es el segundo cambio importante que se encuentra en la obra de Madison: la diferencia entre los intereses permanentes y los temporales. La tarea 
prioritaria es la defensa de aquellos. Siendo así, quien debe llevar la carga principal en la definición de qué es o no lícito no es el legislador y su actividad legiferante, que puede y frecuentemente cede ante las exigencias contingentes o de grupos de poder, sino que debe ser del juez, quien velando por tutelar los intereses permanentes en que se asienta una sociedad y el agregado de intereses de todos sus integrantes, asegure que serán estos y no los cálculos momentáneos o faccionalistas (entendidos como política partidista o de defensa de intereses por encima de los de la justa convivencia), los que prevalecerán (Madison, 1999: 46) (Read, 2000: 47).

Si bien la durabilidad pareciera remitir a un estándar de legitimidad más factual (cosa que se encontrará nuevamente en Max Weber) y no a un examen de reglas categóricas (como en Rousseau, Kant o Rawls), nadie podría negar el valor de someter esa estructuración normativa y la práctica de poder público que de ella surge a un análisis que tenga por medida la prosecución de la vida en sociedad en términos de respeto y dignidad para todos sus integrantes. Para eso hay que lograr un justo equilibrio entre lo necesario para garantizar esos términos y la libertad originaria de las personas; porque menos poderes públicos, por otra parte, no significan más libertad, ya que esta podría estar avasallada por los poderes fácticos o privados (Read, 2000: 25 y 30). Tanto monta a efectos de la ilegitimidad tener poder más allá de la delegación y necesidades del colectivo, como tener insuficiente y que, sobrepasando su propio campo, esos poderes fácticos o privados terminen subordinando los de otras personas, sin que el aparato público pueda impedirlo para reestablecer los ámbitos compatibles de libertad y de dignidad para todos y todas.

El tercer paradigma de interés que marca la obra de Madison se encuentra en su exigencia de que ese amplio programa constitucional debe resolverse en el plano social o empírico y no únicamente mediante postulados jurídicos o la política estatal (Madison, 1999: 49). Como se ve, nos topamos acá con uno de los baluartes más característicos del neoconstitucionalismo; a saber, la necesidad de la aplicabilidad empírica de los preceptos constitucionales o preconstitucionales y su plenitud en las diversas áreas sociales. No basta entonces, que las normas estén declaradas o simbólicamente aceptadas, si es que estas no se traducen en hechos concretos. Tampoco basta que estas presidan o se materialicen en políticas públicas (incluso coactivas), si es que no llegan a todos los espacios de la vida de las personas y, cada vez que se puede escapar al control público o se garantiza la impunidad, los particulares (individual o colectivamente) pisotean y "suspenden" esas coordenadas políticas fundamentales. La verdadera y menos expugnable garantía contra la agresión a esos valores, consiste en su apropiación por parte de la gente, en su vivencia cotidiana, en su cultura jurídica. No en un aparato judicial muy eficiente ni en jueces prominentes, que solo lo son cuando las cosas no andan bien en la sociedad. Nótese que con una mentalidad más de sociólogo de la política que de jurista, Madison incluye entre los actores a los no institucionales o no declarados e incluso las pasiones como factor de importancia (D’addio, 1996: 63-64 y 69). El proyecto constitucional debe mirar, no a su formato o concordancia con ciertos ideales, sino a su funcionamiento efectivo, teniendo en cuenta las pasiones y los intereses de los diversos grupos y sujetos (Madison, 1999: 281). En palabras de Dahl, es imposible 
encontrar una solución puramente constitucional a los inevitables conflictos sociales que suelen tener raíces profundas. En ese sentido, ese autor cree que Madison fue deficitario en algunos aspectos, pues no otorgó toda la atención que debía a los contrapoderes sociales (Dahl, 1970: 22).

En síntesis, en el plan constitucional de Madison el poder público encuentra un límite o borde externo constituido por la soberanía respecto a otros Estados; uno interno, consistente en las libertades originarias de los ciudadanos, que solo se limitan en aras de su convivencia digna; $y$, un borde intermedio que se encarna en los cuerpos intermedios (como pueden ser los estados federados o entes de autonomía local, ya experimentada durante la parte alta de la Colonia y la Revolución como forma de participación ciudadana y de agilización del poder). La ejecutividad no está en la concentración del poder (como decía Montesquieu), sino en la desconcentración.Vale decir que este podría ser el cuarto paradigma importante que modifica el pensamiento de Madison, pero no siendo relevante para el estudio del neoconstitucionalismo, está fuera de nuestro foco de estudio. No obstante, es preciso acotar que también los cuerpos intermedios deben ser fieles observadores y garantes de los valores constitucionales esenciales con los mismos imperativos que el Estado nacional.

Tanto por las razones indicadas acerca del sustento político del orden normativo al igual que dada la complejidad que se ha venido exponiendo no puede pretenderse que el constituyente y ni siquiera el legislador, enlisten todos los poderes o reglas por las que debe regirse la sociedad. El orden constitucional radica en una serie de principios, porque si es de reglas se vuelve inflexible y sujeto a las fluctuaciones de la mayoría transitoria. Aquellos se basan (más) en la razón esta puede serlo (más) en la pasión o ignorancia. Muchos poderes deben quedar confiados a la "implicación" o derivar de los primeros principios, aunque por limitaciones comprensibles, su enumeración no sea posible (Read, 2000: 27).

En suma, el sistema de juridicidad debe estar compuesto por principios y no por reglas o leyes. Y esto nos pone a las puertas de la corriente de neoconstitucionalismo que aquí tratamos de explicar.

\section{b) Zagrebelsky y el neoconstitucionalismo en un mundo cada vez más plural}

La nueva etapa representada por la doctrina neoconstitucionalista o, por lo menos la que me resulta más atractiva y prometedora, se difunde en torno al cambio de milenio y responde más a situaciones extrajurídicas (como es lo normal) que a cuestiones o retos teóricos. La década de los noventa fue especialmente elocuente en lo que a la improductividad política del actual diseño de aparatos públicos se refería. Varias situaciones confluyeron para hacer patente que ese aparato público se había vuelto anquilosado e infértil. Estas van desde las más comunes que son citadas por quienes no ahondan mucho en el tema (como una extendida burocracia y el enquistamiento en ella de sujetos que buscan refugio en la administración pública a falta de talento o dotes para otras ocupaciones) hasta otras más complejas. De estas, destacan a mi 
juicio, cuatro. En orden creciente de densidad teórica, de la primera puede decirse que es la consolidación interna de grupos de poder e interés en ciertas esferas de decisión o de gestión los cuales, para preservar su subsistencia, hacen innecesariamente abigarrado todo procedimiento. Nótese que no es el simple crecimiento o no de la burocracia, sino la generación de grupos internos de poder que se imponen como tales, tanto al universo burocrático como al conglomerado social. Esto no es nuevo. Ya lo había advertido Weber (2001: 14-17).

El segundo factor es de índole comunicativo. A saber, cada sector que interviene en las tomas de decisiones tiene sus propios códigos, lo cual dificulta e incluso inhibe su entendimiento entre esos diversos componentes cada uno de los cuales tiene sus propias construcciones conceptuales, sus propias acepciones e incluso sus propios estándares. Es difícil hacer que en el manejo de un hospital los médicos entiendan las razones de los administradores, o que estos logren comprender plenamente a los ingenieros estructurales, por no hablar de los propios pacientes. Si eso es así en un medio confinado como un hospital, solo basta imaginar cuánto sucede a nivel social. Esto es un poco más nuevo. Como reflexión teórica la desarrolló Luhmann (1995: 45) hacia la década de los 70's y 80's.

Como si ello fuera poco, se agrega la proliferación de intereses. Ya no se puede hablar del interés de "las familias", porque cada familia tiene en su seno componentes individualizables cada uno con su propia posición e intereses. Los intereses de los hijos no tienen necesariamente que coincidir con los del padre, ni los de este con los de la madre. No se puede hablar del "pueblo", de los "proletarios" o las "mujeres", porque estos no existen más que como una construcción expositiva o puramente retórica. Cuando se echa mano a esas categorizaciones generales se está recortando las características de sus partes y estereotipando sus reivindicaciones. Los campesinos, pomposa o románticamente evocados en las décadas precedentes, no existen. Existen campesinos circunstanciados. Es decir, campesinos sin tierra, campesinos con tierra de subsistencia, campesinos con acceso a medios mecánicos, campesinos de productos exportables, campesinos para el mercado interno, campesinos que requieren protección arancelaria, otros que exigen su reducción, etc. Así sucede con casi todos (por no decir que todos) los sectores de la sociedad. Y cada uno de esos sectores con su propia visión de las cosas, de sus derechos en este orden social y tienen sus propios reclamos. Ante ese cuadro heteróclito, tanto el aparato público cuanto la regulación tradicional se vuelve lenta, inapropiada y hasta contraproducente. La ley que regulaba esas actividades se muestra torpemente inadecuada para resolverlo todo $y$, si se aguarda por una reforma idónea para cada ámbito, es probable que no termine viendo la luz. Si a eso se suma que, como se explicó en el párrafo precedente, cada sector genera sus propios códigos de comunicación y entendimiento, el panorama es aun más comprometedor.

El cuarto factor es el acortamiento del tiempo real. No se trata tanto de que los despachos públicos se demoren ahora más que antes (lo cual ha sido estadísticamente falsado en la amplia mayoría de los casos), sino que el flujo casi instantáneo de la información, la competitividad que hace que cada minuto tenga 
valor y el aprovechamiento de cada segundo para algo "productivo", como lo había explicado preclaramente Herbert Marcuse (1998: 78), hace que el aparato público y el diagrama normativo queden desde siempre, desde ya en mora, en débito político.

Por todo eso es que hay quien dice que, al igual que la lectoescritura fue el formato del mundo surgido de la revolución industrial y su producto normativo fue la ley pública, esta ahora exhibe sus limitaciones congénitas en el mundo de la revolución informática y su comunicación audiovisual instantánea.

Lo anterior lleva a replantearse las salidas posibles. Una es la desregulación y exigir que el aparato público saque sus manos de las áreas que se estima más sensibles como serían la economía y la inversión social pública, que es la salida de la derecha (tanto conservadora cuanto la liberal), que aboga por dejar las cosas libradas a las fuerzas "espontáneas", que son cualquier cosa menos eso, espontáneas. Otra es persistir en responder a las nuevas condiciones con las opciones tradicionales, emanando decisiones concentradas, usualmente inadecuadas por su generalidad así como intentando emanar leyes para cada cosa y actividad. La tercera es dar un nuevo contenido al Estado de Derecho, evitando prescindir de la regulación y sin reincidir en el legalismo, reelaborándolo como un Estado Constitucional. Y es aquí donde resulta más interesante la obra del italiano Gustavo Zagrebelsky.

Este se desempeñó como uno de los estudiosos más agudos del Derecho Constitucional en Italia, siendo nombrado en 1995 miembro de la Corte Constitucional cuya presidencia ejercería posteriormente hasta el año 2004.

El diagnóstico de su trabajo empieza por algo que actualmente pocas personas pueden objetar, como es la incertidumbre jurídica reinante. Esto es, la seguridad pretendida por el proyecto jurídico de la modernidad para que las cosas fueran conocidas y entendibles, para que cada quien supiera a qué atenerse para lo cual se requería un ordenamiento en el que la ley reglara todos y cada uno de los aspectos de la vida en sociedad (salvo aquellos que quedaban librados al ámbito individual) y a su vez fuera la cristalización formalizada de la razón, esa seguridad vino a menos y ese proyecto se agotó (Zagrebelsky, 1992: 64). Aquel febril afán de que el ordenamiento tuviera las tres "C" (completo, coherente y claro), pues era la expresión de la razón y de la voluntad soberana vertida en la ley se volvió anquilosado, inidóneo para vérselas con una sociedad cada vez más plural en sus componentes, en los códigos de estos y en la especificidad de sus acciones. Intentar regular cada una de ellas con una normativa general es un despropósito, pues rápidamente se hace visible que dicha regulación general es inadecuada para cada especificidad. Por otra parte, emanar normativas legales específicas para cada una de estas solo viene a incrementar la inflación normativa ya innegable, la dificultad de su aplicación y la incerteza sobre cuáles son las reglas existentes y cómo se resuelven las controversias. En síntesis, el proyecto de reorganización racional de la sociedad, que en el plano jurídico aspiraba a las tres "C" aludidas, paradójicamente terminó acarreando (ante el cambio de las circunstancias sociales), la misma incertidumbre premoderna propia del casuismo y la asistematicidad feudal o preindustrial con que quiso acabar. 
En muchas ocasiones, quizá con ánimo de hacer más comprensible el asunto, se ha dicho que se trata de una superación del esquema francés de arquitectura jurídica surgido de la Revolución el cual como ya se apuntó se asienta en la visión de que, residiendo la soberanía en la Nación, y siendo los legisladores sus representantes (la idea del asamblearismo rápidamente se había abandonado), es la ley la que recoge la voluntad soberana que es la expresión de la razón. Al menos eso es lo que se postulaba. De ahí que la tarea del juez fuera solamente aplicar lo que esa ley prescribía (Montesquieu, 1993: 112). ${ }^{1}$ Los motivos extradoctrinarios para una postura como esa, podían ser de diverso cuño. Básicamente que las constituciones (e incluso la Declaración de Derechos del Hombre) contenían un amplio programa adoptado en momentos de entusiasmo político, pero que con el pasar de los días y la modificación en las correlaciones de poder los grupos hegemónicos intentaron dejar en la penumbra, pasando a ser la ley el factor predominante (Zagrebelsky, 1992: 57). Para decirlo en una nomenclatura que nos es más usual, la Declaración y los postulados constitucionales pasaban al estatus de valoraciones programáticas, no preceptivas.

En el medio estadounidense, por el contrario, lo relevante no era principalmente la ley, sino la constitución alrededor de la cual los diversos estados se habían agrupado y había sido aprobada en las correspondientes consultas ciudadanas. Ese era el acuerdo primario. Ulteriormente, por la organización federal del país, era probable que cada uno de los estados dictara leyes diversas las cuales, so pena de fragmentación, debían tener un marco común que no podía ser otro que la constitución federal y sus sustentos políticos. En este caso, el factor predominante era el control de constitucionalidad que, amén de marcar los pactos mínimos de la sociedad (overlapping consensus, en términos de Rawls), impediría que una composición parlamentaria predominante formalmente legitimada por el consenso popular denegara o atropellara los derechos esenciales que la sociedad en conjunto debía reconocer y tutelar a sus integrantes (D’addio, 1996: 67). Aunque, como se sabe, la lucha por la efectividad de esos principios ha sido ardua y dolorosa con sectores a los que por decenios y siglos se les negó el reconocimiento de los derechos más elementales (mujeres, afroamericanos, aborígenes) y otros que hoy sufren esos atropellos (poblaciones LGTB, inmigrantes, disidentes políticos o religiosos). En nuestras latitudes la experiencia al respecto no es menos descorazonadora. Es suficiente recordar las discusiones recientes sobre el tema de la fecundación in vitro, la muerte asistida, las uniones de personas del mismo sexo, la garantía del acceso al agua, a una adecuada educación, o la seguridad sanitaria de calidad y en tiempo, por ejemplo.

Antes que la constitución sea un proyecto particular de amplio espectro que es rellenado por la ley, el texto fundamental es un marco de pactos mínimos y siempre presentes, aunque no haya ley que los encarne. En vez del Estado de Derecho en la primera acepción que se inclinaba al estatismo, legicentrismo y una interpretación formal, se optó por un Estado Constitucional de Derecho como lo apunta Zagrebelsky (1992: 129) en el que la soberanía estatal se flexibiliza y la interpretación

\footnotetext{
1 "Los jueces de la nación no son, como hemos dicho, más que el instrumento que pronuncia las palabras de la ley, seres inanimados que no pueden moderar ni la fuerza ni el rigor de las leyes".
} 
normativa es más material o sustantiva. En resumen, prevalecen los principios sobre las reglas, correspondiendo a los jueces sobre los legisladores la tarea capital de reconocer esos valores fundamentales en los que se basa la organización social, más que interpretar y aplicar las leyes (que, en todo caso, tanto en su construcción como en su aplicación, deben acomodarse a aquellos). Esa aplicación directa de las normas constitucionales (o incluso preconstitucionales que se hallan implícitas, añadiría Madison), más que controlar el poder público, como postula el esquema del constitucionalismo tradicional, debe orientar y regular la totalidad de las relaciones sociales. Las acciones públicas (ya sean sociales o jurídicas) deben acomodarse a la interpretación más adecuada a la norma constitucional. Como se señaló, se trata de Derecho basado en principios y no reglas (Zagrebelsky, 1992: 147).

A este esquema se ha criticado, hay que reconocer, que causa una gran incerteza, porque los principios son siempre interpretables y se les puede conferir diversas jerarquías entre sí. Sin embargo difícilmente esa inseguridad sería mayor que la hoy sufrida. Por lo demás una cosa sí es cierta: exigiría un mayor esfuerzo de deliberación política (algo de lo que andan tan ayunas nuestras sociedades). Ello permitiría paulatinamente ir uniformando concepciones y sin duda permitiría mejorar la improductividad en la toma de decisiones o resolución de controversias frecuentemente entrampada por el ya socorrido expediente de que no hay ley al respecto o, peor aun, que hay varias que no concuerdan o bien que no se sabe cómo interpretarlas. Creo que nadie escapa de haber vivido esta situación. No puede pretenderse regular la heterogeneidad existente en la actualidad (y que se vislumbra será cada vez más exuberante) con los esquemas o paradigmas de un mundo más homogéneo; que por lo demás nunca fue tal, sino que la diversidad y la disidencia era simplemente invisibilizada, marginada o hasta reprimida. De todas maneras es preciso aceptar que esa concepción flexible o dúctil del Derecho ya está presente entre nosotros desde hace mucho rato y teniendo efectos en los más diversos campos del quehacer cotidiano; si bien no igual en todos, pues el nivel de resistencias y vetos (ya por intereses, ya por concepciones diferentes y sea que estos se expresen en argumentos jurídicos o no), no es parejo en todos los campos.

\section{Saldo evaluativo ${ }^{2}$}

¿Es el neoconstitucionalismo un instrumento ideal para superar la fosilización de la que el ordenamiento jurídico es cada día más sintomático? ¿Estamos hablando de un solo objeto conceptual y doctrinario o de varios? ¿Se trata, antes bien, de diferentes acercamientos al mismo? ¿Al menos será uno que en los años venideros alcanzará un nivel aceptable de univocidad? ¿O sencillamente estamos gastando tinta en una nueva moda, en una nueva ola?

La verdad es que no estoy seguro de ninguna de las respuestas que podría dar a cada cuestionamiento. De lo que sí estoy seguro es que actualmente no se avizora en

\footnotetext{
2 Para una crítica al neoconstitucionalismo, ver el texto de García (en línea).
} 
el horizonte una opción más prometedora. Es cierto: puede que en nuestros medios de cultura jurídica es un planteamiento relativamente incipiente; insuficientemente acabado, de alcances difusos y difuminados; que difícilmente alcanzará un nivel de acotamiento preciso; y quizá el tiempo terminará diciéndonos que, por las razones que sea (inidoneidad de la construcción teórico-conceptual, inadecuación a un medio cultural diferente o por las correlaciones de poder presentes), no era apto para dar respuesta al serio problema de esclerosis que exhibe nuestro ordenamiento jurídico actual, que no era adecuado para flexibilizarlo sin perder la seguridad jurídica (el único valor, que dicho sea de paso, le reconozco al Derecho por sí mismo). Puede que todo ello resulte cierto. Pero en sentido inverso no hay planteamiento político ni jurídico, por muy exitoso o duradero que luego resulte, que no haya empezado así. Es más, las propias construcciones teóricas que hoy se tienen como instituciones cardinales en las variadas ramas del Derecho, están sujetas a esas veleidades. Si no, piénsese en el concepto de la acción penal, de la relación laboral, de la actividad comercial, las potestades administrativas o la noción misma de soberanía en materia constitucional.

De lo que también estoy seguro es que, ante esa esclerosis y el anquilosamiento de algunas posiciones políticas, el neoconstitucionalismo antes expuesto se revela como la vía más inmediata para atender y darles la dignidad que exigen una serie de reivindicaciones que una sociedad, si se quiere reconocer como respetuosa de todos sus componentes, no puede seguir soslayando ni haciendo oídos sordos como es la plena tutela al ambiente, a la solidaridad social, al desarrollo de las facultades de cada individuo y al derecho que cada quien tiene de trazar el plan de su vida personal.

El neoconstitucionalismo no es un programa del "gobierno de los jueces", como algunos detractores le ha endilgado, sino una propuesta flexible para que todos los operadores de Derecho, principalmente los jueces, sean fieles pero también efectivos garantes de los principios constitucionales. 


\section{BIBLIOGRAFÍA}

* D’ADDIO, Mario (1996): Storie delle dottrine politiche, volumen II, ECIG, Génova, 446 pp.

* Dahl, Robert (1970): A preface to democratic theory, University of Chicago Press, Chicago, $154 \mathrm{pp}$.

* García Amado, Juan Antonio (en línea): "Sobre el neoconstitucionalismo y sus precursores". Programa de investigación "Teoría del Derecho y proceso. Sobre los fundamentos normativos de la decisión judicial" del Ministerio de Ciencia y Educación de España, (fecha de consulta 30 de mayo del 2016). Disponible en: http://www.academia.edu/7599793/SOBRE EL NEOCONSTITUCIONALISMO Y SUS PRECURSORES

* Luhmann, Niklas (1995): Poder, Anthropos, Barcelona, 177 pp.

* Madison, James (1999): "Ensayos" 10, 38-43, 47-49, en Alexander Hamilton, John Jay y James Madison, The Federalist Papers, Penguin Books, Nueva York, 606 pp.

* Marcuse, Herbert (1998): Eros and civilization, Beacon, Press Boston, 277 pp.

* Montesquieu, Charles (1993): Del Espiritu de las Leyes, Editorial Tecnos, Madrid, 472 pp.

* Rawls, John (2001): Justice as fairness: a restatement, Belknap Press, Boston, 214 pp.

* ReAD, James (2000): Power versus liberty, University Press of Virginia, Richmond, 201 pp.

* Weber, Max (2001): El Politico y el científico, Ediciones Coyoacán, Ciudad de México, 120 pp.

* Zagrebelsky, Gustavo (1992): Il diritto mite, Einaudi, Turín, 217 pp. 